\title{
IMPLEMENTASI KEBIJAKAN PAMSIMAS DALAM PENYEDIAAN AIR BERSIH BAGI MASYARAKATDI KABUPATEN PATI
}

\section{THE POLICY IMPLEMENTATION OF PAMSIMAS IN PROVIDING CLEAN WATER FOR COMMUNITY IN PATI REGENCY}

\author{
Suroso \\ Kantor Penelitian dan Pengembangan Kabupaten Pati \\ e-mail: suroso_peneliti@yahoo.co.id
}

\begin{abstract}
Accessibility to clean water is the right for all citizens. However some parts of the study area have less access to clean water, especially in the dry season. The objectives of the research are: (1) To analyze the performance of policy implementation for PAMSIMAS in the study area; and (2) To analyze the role of PAMSIMAS in providing clean water for community in the study area. This research uses quantitative approach. The data consist of primary and secondary data. The data collection is conducted by observation and interview. The data analysis uses descriptive one. There are five main findings in the research. First, the coverage of PAMSIMAS includes 109 of 406 villages (26.85\%). Second, the performance in managing PAMSIMAS is fairly good with score 77.37. Third, output of PAMSIMAS programme in 109 villages includes 14,711 installations for clean water of household. Fourth, PAMSIMAS has a capacity 2,850,040 litre per day. Fifth, cashflow of PAMSIMAS is Rp729,219,937.
\end{abstract}

Keywords: clean water, performance, role

\begin{abstract}
ABSTRAK
Akses air bersih merupakan hak setiap warga negara tetapi sebagian kawasan di area studi mengalami kesulitan akses air bersih, khususnya di musim kemarau. Penelitian ini memiliki tujuan: (1) Menganalisa kinerja implementasi kebijakan PAMSIMAS di area studi; dan (2) Menganalisa peran PAMSIMAS dalam penyediaan air bersih bagi masyarakat di area studi. Penelitian ini menggunakan pendekatan kuantitatif. Data penelitian meliputi data primer dan data sekunder. Pengumpulan data primer dilakukan dengan menggunakan teknik wawancara dan pengumpulan data sekunder dilakukan dengan menggunakan teknik observasi dokumen instansi terkait. Teknik analisis data menggunakan analisis deskriptif. Ada beberapa temuan utama dalam penelitian ini. Pertama, coverage PAMSIMAS 109 desa (26,85\%) dari total 406 desa/kelurahan di area studi. Kedua, kinerja tata kelola PAMSIMAS masuk kategori relatif baik dengan skor 77,37. Ketiga, output PAMSIMAS di 109 desa memiliki 14.711 sambungan rumah untuk penyediaan air bersih. Keempat, kapasitas pelayanan air bersih PAMSIMAS di area studi sebanyak 2.850.040 liter per hari yang tersebar di 109 desa. Kelima, BP-PAMS memiliki cash-flow sebanyak Rp729.219.937 dalam pengelolaan PAMSIMAS.
\end{abstract}

Kata kunci: air bersih, kinerja, peran 


\section{PENDAHULUAN}

Sebagian kawasan di Kabupaten Pati mengalami kesulitan memperoleh air bersih, khususnya di musim kemarau. Akses air bersih merupakan hak setiap warga negara. Sesuai perundangundangan yang berlaku, pemerintah berkewajiban menjamin hak setiap warga negara untuk memperoleh air bersih. UU No. 7 Tahun 2004 tentang Sumber Daya Air, Pasal 5 menyatakan bahwa negara menjamin hak setiap orang untuk mendapatkan air bagi kebutuhan pokok minimal sehari-hari guna memenuhi kehidupannya yang sehat, bersih, dan produktif.

Guna mewujudkan amanat UU tersebut, pemerintah membuat kebijakan "Penyediaan Air Minum dan Sanitasi Berbasis Masyarakat (PAMSIMAS)" yang dimulai tahun 2008. Tujuan Pembangunan Millennium Indonesia diantaranya menetapkan bahwa tahun 2015, Indonesia menyediakan akses air minum yang layak bagi $68,87 \%$ penduduk dan akses sanitasi layak bagi $62,41 \%$ penduduk. Kebutuhan air minum, secara nasional Indonesia sampai tahun 2011 baru mampu menyediakan akses yang layak bagi 55,04\% dari total penduduk, sedangkan untuk kebutuhan sanitasi dasar, Indonesia baru mampu menyediakan akses sanitasi layak bagi $55,53 \%$ dari total penduduk. Di antara masyarakat yang belum terlayani, masyarakat berpenghasilan rendah di perdesaan dan pinggiran kota termasuk kelompok yang rentan mengakses air minum dan sanitasi (Kementerian PU, 2013).

\section{Implementasi}

kebijakan

PAMSIMAS Tahun 2008-2012 telah berhasil meningkatkan jumlah warga miskin perdesaan dan pinggiran kota yang dapat mengakses pelayanan air minum dan sanitasi, serta meningkatkan nilai dan perilaku hidup bersih dan sehat melalui upaya pemberdayaan masyarakat. Program lanjutan PAMSIMAS Tahun 2013-2016 merupakan instrumen pelaksanaan dua agenda nasional untuk meningkatkan cakupan penduduk terhadap pelayanan air minum dan sanitasi yang layak dan berkelanjutan, yaitu (1) Air Bersih Untuk Rakyat; dan (2) Sanitasi Total Berbasis Masyarakat. Program ini bertujuan untuk meningkatkan jumlah warga masyarakat kurang terlayani termasuk masyarakat berpenghasilan rendah di perdesaan dan peri-urban yang dapat mengakses pelayanan air minum dan sanitasi, meningkatkan penerapan nilai dan perilaku hidup bersih dan sehat dalam rangka pencapaian target Milennium Development Goals (sektor air minum dan sanitasi) melalui pengarusutamaan dan perluasan pendekatan pembangunan berbasis masyarakat.

Permasalahannya adalah bagaimanakah implementasi kebijakan PAMSIMAS dalam mendukung penyediaan air bersih dan sanitasi bagi masyarakat. Penelitian ini bertujuan untuk: (1) Menganalisa kinerja implementasi kebijakan PAMSIMAS dalam mendukung ketersediaan air bersih dan sanitasi masyarakat; dan (2) Menganalisa peran PAMSIMAS dalam mendukung ketersediaan air bersih dan sanitasi masyarakat di area studi.

\section{TINJAUAN PUSTAKA}

\section{Hakikat PAMSIMAS}

Program PAMSIMAS merupakan program "Penyediaan Air Minum dan Sanitasi Berbasis Masyarakat". Berdasarkan Pedoman Umum PAMSIMAS (Kementerian PU, 2013), Program PAMSIMAS bertujuan untuk meningkatkan jumlah warga masyarakat kurang terlayani termasuk masyarakat berpendapatan rendah di wilayah perdesaan dan peri-urban yang dapat 
mengakses pelayanan air minum dan sanitasi yang berkelanjutan, meningkatkan penerapan nilai dan perilaku hidup bersih dan sehat dalam rangka pencapaian target MDGs (sektor air minum dan sanitasi) melalui pengarusutamaan dan perluasan pendekatan pembangunan berbasis masyarakat. Pengertian "Peri-urban" adalah pinggiran kota yang dapat menjadi lokasi Program Pamsimas dengan karakteristik: (1) Terletak di perbatasan atau pinggiran wilayah kota; (2) Cakupan penduduk dengan akses terhadap fasilitas air minum dan sanitasi yang layak masih rendah; dan (3) Tidak terdapat layanan jaringan PDAM atau PDAL. Selanjutnya, salah satu sasaran program PAMSIMAS adalah minimal 50\% masyarakat dusun (lokasi program) menerapkan Stop Buang Air Besar Sembarangan (BABS).

\section{Implementasi Kebijakan PAMSIMAS}

Kebijakan publik menurut Nugroho (2006) adalah kebijakan yang dibuat oleh administrator negara, atau administrator publik atau segala sesuatu yang dikerjakan dan yang tidak dikerjakan oleh pemerintah. Kebijakan publik berkenaan dengan setiap aturan main dalam kehidupan bersama, baik yang berkenaan dengan hubungan antarwarga maupun antara warga dan pemerintah. Lebih lanjut dikatakan bahwa kebijakan publik sebagai program yang diproyeksikan dengan tujuan tertentu, nilai dan praktik tertentu.

Anderson dalam Subarsono (2005) menyatakan kebijakan publik memiliki beberapa tahap penting: (a) Penetapan agenda kebijakan (agenda setting), dengan menentukan masalah publik yang perlu untuk dipecahkan; (b) Formulasi kebijakan (policy formulation), dengan mengidentifikasi kemungkinan kebijakan yang mungkin digunakan dalam memecahkan masalah; (c) Adopsi kebijakan (policy adoption, dengan menentukan pilihan kebijakan melalui dukungan para administrator dan legislatif. Tahap ini ditentukan melalui tahap suatu proses rekomendasi; (d) Implementasi kebijakan (policy implementation) yaitu suatu tahap dimana kebijakan yang telah diadopsi tadi dilaksanakan oleh unit-unit tertentu dengan memobilisasi dana dan sumber daya yang ada; (e) Penilaian kebijakan (policy assessment). Berbagai unit yang telah ditentukan melakukan penilaian tentang apakah semua proses implementasi telah sesuai atau tidak dengan yang ditentukan.

Implementasi merupakan proses umum tindakan administratif yang dapat diteliti pada tingkat program tertentu. Proses implementasi baru akan dimulai apabila tujuan dan sasaran telah ditetapkan, program kegiatan telah tersusun dan dana telah siap dan disalurkan untuk mencapai sasaran (Grindle,1980). Implementasi kebijakan Program PAMSIMAS dilaksanakan dengan menerapkan 9 prinsip (Pedoman Umum PAMSIMAS, 2013) yaitu: (1) Berbasis Masyarakat, yaitu menempatkan masyarakat sebagai pengambil keputusan utama dan penanggung jawab kegiatan dan pengelolaan sarana air minum dan sanitasi; (2) Tanggap Kebutuhan artinya program PAMSIMAS diberikan kepada lokasi yang membutuhkan dan bersedia memelihara serta mengelola sistem terbangun; (3) Partisipatif, artinya seluruh masyarakat (baik miskin, kaya, perempuan, laki-laki) menjadi pelaku utama dan terlibat secara aktif dalam seluruh tahapan kegiatan PAMSIMAS; (4) Kesetaran gender, artinya Program PAMSIMAS memberikan kesempatan yang sama kepada perempuan maupun laki-laki, untuk mengambil keputusan, berpartisipasi aktif dalam semua kegiatan 
dan bertanggung jawab terhadap pengelolaan sarana air minum dan sanitasi; (5) Keberpihakan pada masyarakat miskin, artinya Program PAMSIMAS memastikan masyarakat miskin mendapatkan akses air minum dan sanitasi yang aman; (6) Akses bagi semua masyarakat, artinya Program PAMSIMAS memastikan semua masyarakat termasuk masyarakat berkebutuhan khusus (disable) dapat mengakses air minum dan sanitasi yang layak dan berkelanjutan;

Keberlanjutan, artinya sarana terbangun dan perubahan perilaku memberikan manfaat secara menerus, berkelanjutan sejak awal pelaksanaan program; (8) Transparansi dan akuntabilitas, artinya pelaksanaan kegiatan dan pengelolaan sarana dilakukan secara terbuka dan dapat dipertanggungjawabkan; dan (9) Berbasis nilai, artinya Program PAMSIMAS diselenggarakan dengan berlandaskan nilai-nilai luhur terutama kejujuran, dapat dipercaya, tanpa pamrih, dan gotong royong.

\section{Standar Normatif Kebutuhan Air}

Standar kebutuhan masyarakat terhadap air bervariasi antara kawasan satu dengan kawasan lainnya. Kebutuhan air masyarakat kota relatif lebih besar dari masyarakat desa. Menurut Kementerian PU (1996), ada 5 klasifikasi standar kebutuhan air, konsumsi unit Sambungan Rumah (SR): (1) Konsumsi di kota metropolitan sebanyak >150 liter/orang/hari; (2) Konsumsi di kota besar sebanyak 120- 150 liter/orang/hari; (3) Konsumsi di kota sedang sebanyak 90-120 liter/orang/hari; (4) Konsumsi di kota kecil sebanyak 80-120 liter/orang/hari; dan (5) Konsumsi di desa sebanyak 60-80 liter/orang/hari.

Selanjutnya, Badan Standardisasi Nasional (2002) menyatakan bahwa penggunaan air untuk keperluan domestik diperhitungkan dari jumlah penduduk di daerah perkotaan dan pedesaan. Penduduk perkotaan memerlukan 120 liter/hari/kapita, sedang penduduk pedesaan memerlukan 60 liter/hari/kapita maka kebutuhan air dapat dikalkulasi dan direncanakan.

\section{METODE PENELITIAN}

Penelitian ini menggunakan pendekatan kuantitatif. Penelitian ini memiliki lokus di Kabupaten Pati. Data penelitian meliputi data primer dan data sekunder. Pengumpulan data primer dilakukan dengan menggunakan teknik wawancara. Pengumpulan data sekunder dilakukan dengan menggunakan teknik observasi dokumen instansi terkait. Teknik analisis data menggunakan analisis deskriptif.

\section{HASIL DAN PEMBAHASAN}

\section{Eksistensi dan Perkembangan PAMSIMAS}

Program Penyediaan Air Minum dan Sanitasi Berbasis Masyarakat (PAMSIMAS) dilaksanakan mulai tahun 2008. Kabupaten Pati tahun 2008 memperoleh program PAMSIMAS untuk 9 desa. Tahun 2009 ada 11 desa yang memperoleh program PAMSIMAS. Tahun 2010 ada 18 desa yang memperoleh program PAMSIMAS. Sampai Tahun 2014 ada 109 desa yang memperoleh program PAMSIMAS yang ditunjukkan Tabel 1. 
Tabel 1.

Eksistensi dan Perkembangan PAMSIMAS di Kabupaten Pati

\begin{tabular}{|c|c|c|c|c|c|c|c|c|c|}
\hline \multirow{2}{*}{ No } & \multirow{2}{*}{ Kecamatan } & \multicolumn{7}{|c|}{ Jumlah Desa Memperolah PAMSIMAS } & \multirow{2}{*}{$\begin{array}{l}\text { Jumlah } \\
\text { PAMSI } \\
\end{array}$} \\
\hline & & 2008 & 2009 & 2010 & 2011 & 2012 & 2013 & 2014 & \\
\hline 1 & Sukolilo & 1 & 1 & 2 & 2 & 1 & 1 & 1 & 9 \\
\hline 2 & Kayen & & 1 & 1 & & & 4 & 3 & 9 \\
\hline 3 & Tambakromo & & & 3 & 1 & 1 & 1 & & 6 \\
\hline 4 & Winong & & 1 & 1 & 1 & 1 & 1 & 3 & 8 \\
\hline 5 & Pucakwangi & 1 & 2 & 1 & 2 & 2 & 2 & 3 & 13 \\
\hline 6 & Jaken & & 1 & 2 & 1 & & 1 & 2 & 7 \\
\hline 7 & Batangan & 1 & & 1 & 1 & 2 & & & 5 \\
\hline 8 & Juwana & 1 & & & & & & & 1 \\
\hline 9 & Jakenan & 1 & 1 & 1 & 1 & 2 & 1 & & 7 \\
\hline 10 & Pati & & & & & & & & 0 \\
\hline 11 & Gabus & & 1 & 1 & & 3 & 2 & & 7 \\
\hline 12 & Margorejo & 1 & & & & 1 & & & 2 \\
\hline 13 & Gembong & 1 & 1 & 1 & 2 & 1 & 1 & & 7 \\
\hline 14 & Tlogowungu & 1 & 1 & & 2 & 1 & 3 & & 8 \\
\hline 15 & Wedarijaksa & & & & & & & & 0 \\
\hline 16 & Trangkil & & & & & & & & 0 \\
\hline 17 & Margoyoso & 1 & & 1 & & & 1 & & 3 \\
\hline 18 & Gunungwungkal & & 1 & 2 & 1 & & 3 & & 7 \\
\hline 19 & Cluwak & & & 1 & 2 & 1 & 2 & & 6 \\
\hline 20 & Tayu & & & & & 1 & & & 1 \\
\hline \multirow[t]{2}{*}{21} & Dukuhseti & & & & & 1 & 1 & 1 & 3 \\
\hline & Kabupaten Pati & 9 & 11 & 18 & 16 & 18 & 24 & 13 & 109 \\
\hline
\end{tabular}

Sumber: Bappermades Kab. Pati (2015)

\section{Kinerja Tata Kelola PAMSIMAS}

Tata kelola PAMSIMAS dilaksanakan oleh masyarakat. Kebijakan ini memiliki tujuan: (a) Memampukan masyarakat untuk mengorganisasi dirinya, merencanakan, mengelola dan menjaga keberlanjutan pelayanan air minum dan sanitasi yang aman; (b) Memperkuat kapasitas kelembagaan masyarakat dalam rangka menjamin kualitas pengelolaan pelayanan air minum dan sanitasi di desa/kelurahan; dan (c) Membangun komitmen dan kapasitas pemerintah kabupaten/kota dan provinsi dalam peningkatan kinerja sistem pengelolaan pelayanan air minum dan sanitasi perdesaan berbasis masyarakat yang berkelanjutan melalui pengarusutamaan PAMSIMAS dalam kebijakan pembangunan air minum dan sanitasi.

Pengukuran kinerja tata kelola PAMSIMAS mengggunakan scoring system. Parameter pengukuran tata kelola PAMSIMAS menggunakan status kinerja Badan Pengelola Penyediaan Air Minum dan Sanitasi (BP-PAMS) yang diklasifikasikan menjadi 3 kategori: (a) Status kinerja "Tumbuh" dengan skor 1; (b) Status kinerja "Berkembang" dengan skor 2; dan (c) Status kinerja "Mandiri" dengan skor 3 .

Kecamatan Sukolilo misalnya, memiliki 9 desa yang memperoleh program PAMSIMAS dengan status skor kinerja BP-PAMS: (a) Desa Pakem dengan status kinerja Mandiri; (b) Desa Prawoto dengan status kinerja Tumbuh; (c) Desa Kuwawur dengan status kinerja Mandiri; (d) Desa Porangparing dengan 
status kinerja Berkembang; (e) Desa Sumbersoko dengan status kinerja Mandiri; (f) Desa Tompegunung dengan status kinerja Berkembang; (g) Desa Gadudero dengan status kinerja Mandiri; (h) Desa Sukolilo dengan status kinerja Mandiri; dan (i) Desa Kedungwinong dengan status kinerja Berkembang. Oleh karena itu, kumulatif kinerja tata kelola PAMSIMAS dalam scoring system dari 9 desa berjumlah 22 dan bila skor kriteria 27 (9 desa x 3 skor tertinggi) maka skor kinerja relatif sebesar 81,48 yang berasal dari 22 dibagi 27. Kawasan lain dianalisa dengan cara yang sama dan ditunjukkan Tabel 2.

Tabel 2 menunjukkan kinerja tata kelola PAMSIMAS 109 desa yang memiliki kumulatif skor 253 dan bila skor kriteria 327 yang berasal dari 109 kali 3 maka capaian kinerja relatif sebesar 77,37. Status kinerja 77,37 lebih dekat dengan status kinerja berkembang.

Tabel 2.

Kinerja Tata Kelola PAMSIMAS di Kabupaten Pati

\begin{tabular}{|c|c|c|c|c|c|}
\hline \multirow{2}{*}{ No } & \multirow{2}{*}{ Kecamatan } & \multicolumn{2}{|c|}{ Desa Memiliki PAMSIMAS } & \multirow{2}{*}{$\begin{array}{c}\text { Kriteria } \\
\text { Skor }(n \times \text { 3) } \\
\end{array}$} & \multirow{2}{*}{$\begin{array}{c}\text { Skor Relatif } \\
\text { Kinerja }\end{array}$} \\
\hline & & Jumla Desa & Kum. skor & & \\
\hline 1 & Sukolilo & 9 & 22 & 27 & 81,48 \\
\hline 2 & Kayen & 9 & 11 & 27 & 40,74 \\
\hline 3 & Tambakromo & 6 & 15 & 18 & 83,33 \\
\hline 4 & Winong & 8 & 14 & 24 & 58,33 \\
\hline 5 & Pucakwangi & 13 & 26 & 39 & 66,67 \\
\hline 6 & Jaken & 7 & 15 & 21 & 71,43 \\
\hline 7 & Batangan & 5 & 13 & 15 & 86,67 \\
\hline 8 & Juwana & 1 & 2 & 3 & 66,67 \\
\hline 9 & Jakenan & 7 & 19 & 21 & 90,48 \\
\hline 10 & Pati & 0 & & & \\
\hline 11 & Gabus & 7 & 18 & 21 & 85,71 \\
\hline 12 & Margorejo & 2 & 6 & 6 & 100,00 \\
\hline 13 & Gembong & 7 & 20 & 21 & 95,24 \\
\hline 14 & Tlogowungu & 8 & 22 & 24 & 91,67 \\
\hline 15 & Wedarijaksa & 0 & & & \\
\hline 16 & Trangkil & 0 & & & \\
\hline 17 & Margoyoso & 3 & 8 & 9 & 88,89 \\
\hline 18 & Gunungwungkal & 7 & 16 & 21 & 76,19 \\
\hline 19 & Cluwak & 6 & 17 & 18 & 94,44 \\
\hline 20 & Tayu & 1 & 3 & 3 & 100,00 \\
\hline \multirow[t]{2}{*}{21} & Dukuhseti & 3 & 6 & 9 & 66,67 \\
\hline & Kabupaten Pati & 109 & 253 & 327 & 77,37 \\
\hline
\end{tabular}

Sumber: Pengolahan Data (2016) dan Bappermades (2015) 
Peran PAMSIMAS dalam Penyediaan Air Bersih bagi Masyarakat

Peran PAMSIMAS dalam mendukung ketersediaan air bersih dan sanitasi masyarakat diukur dengan scoring system. Parameter pengukuran daya dukung PAMSIMAS terhadap ketersediaan air bersih dan sanitasi masyarakat menggunakan ukuran banyaknya Sambungan Rumah (SR) dari jaringan pelayanan air.

Kabupaten Pati memiliki 109 desa yang memperoleh program PAMSIMAS dan secara kumulatif ada 14.711 sambungan rumah penyediaan air bersih dari program ini. Sambungan rumah (SR) dengan rasio tertinggi berada di
Kecamatan Winong dengan besaran rasio 1,91. Ini berarti di kawasan ini memiliki sambungan rumah hampir 2 kali lipat dibanding rerata sambungan rumah di kawasan lain yang ditunjukkan pada Tabel 3.

Nilai rasio proporsi 1 sama dengan rerata (kabupaten) dan bila suatu kawasan memiliki nilai rasio proporsi kurang dari 1 berarti peran PAMSIMAS relatif lebih kecil dari rerata. Sebaliknya bila suatu kawasan memiliki nilai rasio proporsi lebih dari 1 berarti peran PAMSIMAS relatif lebih baik dalam penyediaan air bersih dan sanitasi masyarakat

Tabel 3.

Peran PAMSIMAS dalam Penyediaan Air Bersih dan Sanitasi Masyarakat

\begin{tabular}{|c|c|c|c|c|c|c|c|}
\hline \multirow[t]{2}{*}{ No } & \multirow[t]{2}{*}{ Kecamatan } & \multicolumn{2}{|c|}{$\begin{array}{c}\text { Desa dengan } \\
\text { Pamsimas } \\
\end{array}$} & \multicolumn{2}{|c|}{ Sambungan Rumah } & \multirow{2}{*}{$\begin{array}{c}\text { Ratio } \\
\text { Proporsi }\end{array}$} & \multirow[t]{2}{*}{ Ket } \\
\hline & & Pamsimas & Proporsi & Pamsimas & Proporsi & & \\
\hline 1 & Sukolilo & 9 & 8,26 & 615 & 4,18 & 0,51 & \multirow{9}{*}{ terbaik } \\
\hline 2 & Kayen & 9 & 8,26 & 531 & 3,61 & 0,44 & \\
\hline 3 & Tambakromo & 6 & 5,50 & 731 & 4,97 & 0,90 & \\
\hline 4 & Winong & 8 & 7,34 & 2.065 & 14,04 & 1,91 & \\
\hline 5 & Pucakwangi & 13 & 11,93 & 896 & 6,09 & 0,51 & \\
\hline 6 & Jaken & 7 & 6,42 & 648 & 4,40 & 0,69 & \\
\hline 7 & Batangan & 5 & 4,59 & 750 & 5,10 & 1,11 & \\
\hline 8 & Juwana & 1 & 0,92 & 0 & 0,00 & 0,00 & \\
\hline 9 & Jakenan & 7 & 6,42 & 1.232 & 8,37 & 1,30 & \\
\hline 10 & Pati & 0 & & & & & \\
\hline 11 & Gabus & 7 & 6,42 & 1027 & 6,98 & 1,09 & \\
\hline 12 & Margorejo & 2 & 1,83 & 366 & 2,49 & 1,36 & \\
\hline 13 & Gembong & 7 & 6,42 & 1082 & 7,36 & 1,15 & \\
\hline 14 & Tlogowungu & 8 & 7,34 & 1489 & 10,12 & 1,38 & \\
\hline 15 & Wedarijaksa & 0 & & & & & \\
\hline 16 & Trangkil & 0 & & & & & \\
\hline 17 & Margoyoso & 3 & 2,75 & 689 & 4,68 & 1,70 & \\
\hline 18 & Gunungwungkal & 7 & 6,42 & 794 & 5,40 & 0,84 & \\
\hline 19 & Cluwak & 6 & 5,50 & 1.164 & 7,91 & 1,44 & \\
\hline 20 & Tayu & 1 & 0,92 & 211 & 1,43 & 1,56 & \\
\hline 21 & Dukuhseti & 3 & 2,75 & 421 & 2,86 & 1,04 & \\
\hline & Kabupaten Pati & 109 & 100,00 & 14.711 & 100,00 & 1,00 & \\
\hline
\end{tabular}

Sumber: Bappermades Kab. Pati (2015). 
Setelah mengetahui banyaknya Sambungan Rumah (SR) air bersih PAMSIMAS maka kapasitas air yang dikonsumsi masing-masing kawasan dapat diperhitungkan. BSN (2002) menyampaikan bahwa konsumsi air masyarakat desa sebanyak 60 liter/orang/hari.

Kabupaten Pati memiliki 14.711 sambungan rumah air bersih dari
PAMSIMAS. Penduduk Tahun 2015 (BPPKB, 2015) sebanyak 1.371.052 orang dan jumlah KK sebanyak 424.616 yang berarti rerata KK 3,23 orang. Oleh karena itu, kapasitas pelayanan air bersih PAMSIMAS di Kabupaten Pati sebanyak 2.850.040 liter per hari yang berasal dari (3,23 x 60 liter x 14.711 SR). Persebaran kapasitas pelayanan air bersih dari PAMSIMAS ditunjukkan Tabel 4.

Tabel 4.

Kapasitas PAMSIMAS dalam Pelayanan Penyediaan Air Bersih

\begin{tabular}{lcccccc}
\hline Kecamatan & $\begin{array}{c}\text { SR } \\
\text { Pamsimas }\end{array}$ & $\begin{array}{c}\text { Penduduk } \\
\text { BPPKB, 2015 }\end{array}$ & $\begin{array}{c}\text { Jumlah } \\
\text { KK }\end{array}$ & $\begin{array}{c}\text { Rerata } \\
\text { KK }(\mathbf{o r g})\end{array}$ & $\begin{array}{c}\text { Konsumsi } \\
\text { Air (L/O/h) }\end{array}$ & $\begin{array}{c}\text { Kapasitas } \\
\text { PAMS }\end{array}$ \\
\hline Sukolilo & 615 & 91.082 & 28.951 & 3,15 & 60 & 116.090 \\
Kayen & 531 & 80.878 & 24.085 & 3,36 & 60 & 106.987 \\
Tambakromo & 731 & 58.672 & 17.136 & 3,42 & 60 & 150.172 \\
Winong & 2.065 & 69.711 & 22.681 & 3,07 & 60 & 380.812 \\
Pucakwangi & 896 & 51.102 & 15.690 & 3,26 & 60 & 175.095 \\
Jaken & 648 & 49.530 & 15.572 & 3,18 & 60 & 123.666 \\
Batangan & 750 & 47.509 & 15.006 & 3,17 & 60 & 142.470 \\
Juwana & 0 & 94.981 & 29.704 & 3,20 & 60 & - \\
Jakenan & 1.232 & 49.182 & 16.918 & 2,91 & 60 & 214.891 \\
Pati & & 107.287 & 32.326 & 3,32 & 60 & - \\
Gabus & 1027 & 66.423 & 19.861 & 3,34 & 60 & 206.082 \\
Margorejo & 366 & 60.861 & 19.238 & 3,16 & 60 & 69.472 \\
Gembong & 1082 & 50.723 & 14.782 & 3,43 & 60 & 222.767 \\
Tlogowungu & 1489 & 56.021 & 17.931 & 3,12 & 60 & 279.121 \\
Wedarijaksa & & 65.350 & 20.538 & 3,18 & 60 & - \\
Trangkil & & 69.253 & 20.878 & 3,32 & 60 & - \\
Margoyoso & 689 & 77.167 & 23.279 & 3,31 & 60 & 137.037 \\
Gngwungkal & 794 & 40.231 & 12.269 & 3,28 & 60 & 156.215 \\
Cluwak & 1.164 & 51.917 & 16.118 & 3,22 & 60 & 224.959 \\
Tayu & 211 & 71.101 & 22.222 & 3,20 & 60 & 40.507 \\
Dukuhseti & 421 & 62.071 & 19.431 & 3,19 & 60 & 80.691 \\
\hline Kab. Pati & 14.711 & 1.371 .052 & 424.616 & 3,23 & 60 & 2.850 .040 \\
\hline Sumber: Bappering
\end{tabular}

Sumber: Bappermades Kab. Pati (2015) 


\section{Prospek Keberlanjutan dan Pengembangan PAMSIMAS}

Prospek keberlanjutan dan pengembangan PAMSIMAS dapat dicermati dari kondisi dan eksistensi uang kas (cash-flow) yang dimiliki. Pengelolaan PAMSIMAS membutuhkan biaya operasional dan bila cash-flow relatif besar maka ada potensi lebih baik untuk berkelanjutan dan berkembang termasuk dalam pemeliharaan jaringan dan perluasan jaringan Sambungan Rumah (SR).

Pembayaran atas sambungan rumah dari akses air bersih dari PAMSIMAS ditentukan sendiri oleh masyarakat atas dasar musyawarah. Berdasarkan saldo keuangan PAMSIMAS pada 109 desa di Kabupaten Pati sebesar Rp729.219.937. Kecamatan Kayen misalnya, memiliki
531 sambungan rumah PAMSIMAS $(3,61 \%)$ dari total 14.711 SR (kabupaten) dan saldo kas yang dimiliki sebesar Rp2.781.000 (0,38\%) dari total saldo Rp729.219.937 (kabupaten). Oleh karena itu rasio proporsi saldo sebesar 0,11 yang berarti ada kerentanan PAMSIMAS di kawasan ini untuk bermasalah atau potensi keberlanjutannya kecil. Distribusi saldo dan prospek keberlanjutan PAMSIMAS ditunjukkan Tabel 5.

Rasio proporsi kepemilikan saldo terbesar berada di Kecamatan Margorejo. Ini berarti ada indikasi kesadaran masyarakat di Kecamatan Margorejo relatif lebih baik dari kawasan lain dalam upaya melestarikan dan mengembangkan program PAMSIMAS. Masyarakat bersepakat melakukan iuran rutin relatif lebih besar dari kawasan lainnya.

Tabel 5.

Prospek Keberlanjutan dan Pengembangan PAMSIMAS

\begin{tabular}{clccccc}
\hline \multirow{2}{*}{ No } & \multirow{2}{*}{ Kecamatan } & \multicolumn{2}{c}{ Sambungan Rumah } & \multicolumn{2}{c}{ Kepemilikan Saldo } & Rasio \\
\cline { 3 - 6 } & & Pamsimas & $\mathbf{\%}$ & Jumlah $(\mathbf{R p})$ & $\mathbf{\%}$ & Proporsi \\
\hline 1 & Sukolilo & 615 & 4,18 & 30.825 .800 & 4,23 & 1,01 \\
2 & Kayen & 531 & 3,61 & 2.781 .000 & 0,38 & 0,11 \\
3 & Tambakromo & 731 & 4,97 & 16.266 .000 & 2,23 & 0,45 \\
4 & Winong & 2.065 & 14,04 & 20.850 .000 & 2,86 & 0,20 \\
5 & Pucakwangi & 896 & 6,09 & 28.910 .077 & 3,96 & 0,65 \\
6 & Jaken & 648 & 4,40 & 17.905 .000 & 2,46 & 0,56 \\
7 & Batangan & 750 & 5,10 & 21.779 .800 & 2,99 & 0,59 \\
8 & Juwana & 0 & 0,00 & 0 & 0,00 & 0,00 \\
9 & Jakenan & 1.232 & 8,37 & 81.129 .600 & 11,13 & 1,33 \\
10 & Pati & & & & & \\
11 & Gabus & 1027 & 6,98 & 66.055 .120 & 9,06 & 1,30 \\
12 & Margorejo & 366 & 2,49 & 60.403 .961 & 8,28 & 3,33 \\
13 & Gembong & 1082 & 7,36 & 153.387 .518 & 21,03 & 2,86 \\
14 & Tlogowungu & 1489 & 10,12 & 76.875 .661 & 10,54 & 1,04 \\
15 & Wedarijaksa & & & & & \\
16 & Trangkil & & & & & \\
17 & Margoyoso & 689 & 4,68 & 45.575 .878 & 6,25 & 1,34 \\
18 & Gunungwungkal & 794 & 5,40 & 9.597 .200 & 1,32 & 0,24 \\
19 & Cluwak & 1.164 & 7,91 & 67.246 .772 & 9,22 & 1,17 \\
20 & Tayu & 211 & 1,43 & 22.990 .000 & 3,15 & 2,20 \\
21 & Dukuhseti & 421 & 2,86 & 6.640 .550 & 0,91 & 0,32 \\
\hline & Kabupaten Pati & 14.711 & 100,00 & 729.219 .937 & 100,00 & 1,00 \\
\hline
\end{tabular}

Sumber: Bappermades Kab. Pati (2015) 


\section{KESIMPULAN DAN SARAN}

\section{Kesimpulan}

Ada beberapa kesimpulan dalam penelitian ini. Pertama, sampai tahun 2014 ada 109 desa yang memperoleh program penyediaan air bersih dan sanitasi berbasis masyarakat (PAMSIMAS). Ini berarti coverage PAMSIMAS di Kabupaten Pati sebesar 26,85\% dari total 406 desa/kelurahan. Kedua, kinerja tata kelola PAMSIMAS di Kabupaten Pati masuk kategori relatif baik dengan skor 77,37. Ketiga, program PAMSIMAS di Kabupaten Pati memiliki 14.711 sambungan rumah air bersih. Keempat, kapasitas pelayanan air bersih PAMSIMAS di Kabupaten Pati sebanyak 2.850.040 liter per hari yang tersebar di 109 desa. Kelima, Badan Pengelola Penyediaan Air Minum dan Sanitasi (BPPAMS) secara kumulatif di Kabupaten Pati memiliki cash-flow sebesar Rp729.219.937 dari pelaksanaan program PAMSIMAS.

\section{Saran}

Guna mendukung keberlanjutan program PAMSIMAS perlu dilakukan tindakan yang relevan. Pertama, kinerja tata kelola PAMSIMAS sebagian kawasan relatif kurang baik seperti di Kecamatan Kayen dengan skor 40,74 dan Kecamatan Winong dengan skor 58,33. Guna menguatkan tata kelola PAMSIMAS, perlu ada pendampingan BP-PAMS di kawasan tersebut. Kedua, output program PAMSIMAS di sebagian kawasan relatif kurang baik, seperti Juwana tidak memiliki sambungan rumah pelayanan air bersih dan Kecamatan Kayen dengan ratio 0,44 yang jauh dibawah rata-rata. Guna meningkatkan output sambungan rumah (SR), BP-PAMS perlu dilatih atau didorong ada penyegaran/reshuffle kepengurusan. Ketiga, prospek keberlanjutan dan pengembangan
PAMSIMAS di sebagian kawasan relatif kurang baik, misalnya Kecamatan Kayen memiliki rasio proporsi cash-flow hanya 0,11 dan Kecamatan Winong memiliki rasio proporsi cash-flow 0,20. Kondisi ini rentan tidak mampu melakukan pemeliharaan sarana PAMSIMAS dan sulit untuk mengembangkan jaringan sambungan rumah (SR) maka batas minimum iuran atas penggunaan air agar diupayakan.

\section{DAFTAR PUSTAKA}

Badan Pemberdayaan Masyarakat dan Desa. 2015. Profil Lembaga Ekonomi Masyarakat Desa. Pati: Bappermades Kabupaten Pati.

Badan Pemberdayaan Perempuan dan Keluarga Berencana. 2015. Pendataan Keluarga. Pati: BPPKB Kabupaten Pati.

Badan Standardisasi Nasional. 2002. Penyusunan Neraca Sumber Daya Bagian 1: Sumber Daya Air Spasial. Jakarta: Badan Standardisasi Nasional.

Grindle, M. S. 1980. Politics and a Policy Implementation in the Third World. New Jersey: Princetown University Press.

Kementerian Pekerjaan Umum. 2013. Pedoman Pengelolaan Program PAMSIMAS. Jakarta: Ditjen Cipta Karya.

Perencanaan Air Bersih. Jakarta: Ditjen Cipta Karya.

Nugroho, R. 2006. Kebijakan Publik Untuk Negara-Negara Berkembang. Jakarta: Gramedia Pustaka.

Subarsono, A. G. 2005. Analisis Kebijakan Publik: Teori dan Aplikasi. Yogyakarta: Pustaka Pelajar. 
Undang-Undang Nomor 7 Tahun 2004 tentang Sumber Daya Air.

\section{BIODATA PENULIS}

Suroso, lahir 19 Maret 1966 di

Kabupaten Pati Jawa Tengah. Magister

Perencanaan Kota dan Daerah

Universitas Gajah Mada. Bekerja di

Kantor Penelitian dan Pengembangan

Kabupaten Pati sebagai Peneliti Madya. 